\title{
The Schnitzler Syndrome - A Treatment at Last?
}

\author{
D. Lipsker \\ Clinique dermatologique, Hôpitaux universitaires, Strasbourg, France
}

L. Schnitzler, a French dermatologist, first described the Schnitzler syndrome in 1972 [1]. It is a disabling chronic disorder defined by the presence of an urticarial eruption and a monoclonal IgM gammopathy as well as at least 2 other signs among the following: fever, bone pain, joint pain, abnormal findings on bone morphological investigations, palpable lymph nodes, spleen and/or liver enlargement, leukocytosis or an elevated erythrocyte sedimentation rate [2]. Chronic inflammation can induce severe symptomatic inflammatory anemia [3]. The diagnosis relies on this combination of clinical, biological and radiological findings as well as on exclusion of the hyperIgD syndrome, adult-onset Still disease, urticarial hypocomplementemic vasculitis, acquired $\mathrm{C} 1$ inhibitor deficiency and cryoglobulinemia. Although the syndrome is probably underdiagnosed, it is a rare disease and less than 60 cases have been reported.

The course of the disease is long-standing, and neither spontaneous nor treatment-induced remissions have been reported. At least $15 \%$ of the patients with a Schnitzler syndrome will eventually develop a lymphoproliferative disorder, although this percentage would probably be much higher if longer follow-up periods were to be considered.

The pathophysiology of the syndrome remains unclear. The clonal IgM proliferation is deposited in the skin and could play a role in the pathophysiology of the skin rash [4]. The presence of anti-IL-1 antibodies as well as elevated serum IL-6 and IL-2 receptor levels were reported with increased frequency $[2,5]$. Although IL-6 is an essen- tial plasma cell growth factor, it is also an acute-phase reactant and its increase during a systemic illness is therefore not surprising. Thus, it remains to be established if the clonal IgM proliferation is primitive in nature or the result of a continuous antigenic stimulation so that the question remains open whether the Schnitzler syndrome shoulb be considered as a 'smoldering' mature B cell dyscrasia.

Treatment of the Schnitzler syndrome is disappointing and difficult. There is a long list of treatments (reviewed in Lipsker et al. [2]), including nonsteroidal anti-inflammatory drugs (NSAIDs), steroids at acceptable dosages, immunosuppressive drugs, antihistamines, colchicine, dapsone, antimalarials, intravenous immunoglobulins, plasmapheresis and PUVA therapy, that did not constantly prove efficient in controlling the skin rash or the other signs of the disease. Thus, the report by Schartz et al. [6] about the efficiency of interferon $\alpha$ to treat this disorder is noteworthy. The authors report a 51-year-old man who fulfilled the criteria for the diagnosis of the Schnitzler syndrome. The patient's symptoms did not respond to antihistamines, NSAIDs, steroids, UVA1 full-body phototherapy and plasmapheresis. However, $5 \mathrm{MU}$ of interferon $\alpha_{2 b}$ administered 3 times weekly proved rapidly efficient to control the skin rash and the bone pain, although interferon did not prevent an increase in the IgM level during an 18-month treatment period. When interferon was stopped, the rash recurred, strongly suggesting that improvement was not coincidental. Two features were unusual in the observation presented by Schartz et al. [6]:

\begin{tabular}{ll}
\hline KARGER & ( ) 2002 S. Karger AG, Basel \\
$1018-8665 / 02 / 2051-0001 \$ 18.50 / 0$ \\
$\begin{array}{l}\text { Fax +4161306 1234 } \\
\text { E-Mail karger@karger.ch } \\
\text { www.karger.com }\end{array}$ & $\begin{array}{l}\text { Accessible online at: } \\
\text { www.karger.com/journals/drm }\end{array}$
\end{tabular}

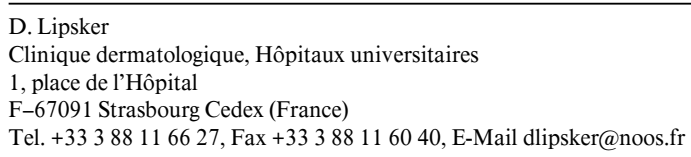


the patient had hypereosinophilia and a monoclonal medullar plasmacytosis of 10-15\%. These 2 findings suggest a 'smoldering' plasma cell dyscrasia and this patient should be monitored carefully.

How interferon relieves the symptoms of this syndrome remains to be established. As the pathophysiology of the Schnitzler syndrome is not understood, it is difficult to focus on a potential target of interferon. Authors suggest that efficiency might be related to interferoninduced downregulation of circulating IL-1 levels. However, interferon is a 'broad-spectrum' immunomodulating drug that induces much more changes than merely downregulating IL-1 levels. It should not be forgotten that interferon proved of some value in the treatment of patients with myeloma [7] and that this drug is able to induce plasma cell apoptotis [8]. Thus, it cannot be excluded that interferon exercises a direct action on the clonal plasma cell proliferation, although it did not prevent an increase in the IgM levels in this patient with elevated medullar plasmacytosis.

The observation that interferon $\alpha$ relieved the symptoms of one patient with the Schnitzler syndrome is important. The future will tell us if interferon will be efficient in more patients with this syndrome, although Kuenzli et al. [9] have already made a similar observation in another patient. Therefore, as there is unfortunately no other efficient treatment available, if first-line treatments like NSAIDs, colchicine, antimalarials or dapsone fail to control the symptoms, interferon treatment certainly deserves to be tried in more patients with this rare syndrome.

\section{References}

1 Schnitzler L: Lésions urticariennes chroniques permanentes (érythème pétaloïde?) Cas cliniques, No 46 B. Journée Dermatologique d'Angers, octobre 1972.

2 Lipsker D, Veran Y, Grunenberger F, Cribier B, Heid E, Grosshans E: The Schnitzler syndrome: Four new cases and review of the literature. Medicine 2001;80:37-44.

3 Berdy SS, Bloch KJ: Schnitzler's syndrome: A broader clinical spectrum. J Allergy Clin Immunol 1991;87:849-854.
4 Lipsker D, Spehner D, Drillien R, Schmitt P, Cribier B, Heid E, Humbel RL, Grosshans E: Schnitzler syndrome: Heterogeneous immunopathological findings involving IgM-skin interactions. Br J Dermatol 2000;142:954-959.

5 Saurat JH, Schifferli J, Steiger G, Dayer JM, Didierjean L: Anti-interleukin-1 alpha autoantibodies in humans: Characterization, isotype distribution, and receptor-binding inhibition Higher frequency in Schnitzler's syndrome (urticaria and macroglobulinemia). J Allergy Clin Immunol 1991;88:244-256.

6 Schartz NEC, Buder S, Sperl H, Audring H, Paus R, Tebbe B, Krüger K, Sterry W: Report of one case of Schnitzler's syndrome treated successfully with interferon alfa-2b. Dermatology 2002;205:54-56.
7 Anonymous: Interferon as therapy for multiple myeloma: An individual patient data overview of 24 randomized trials and 4,012 patients. $\mathrm{Br} \mathrm{J}$ Haematol 2001;113:1020-1034.

8 Chen Q, Gong B, Mahmoud-Ahmed AS, Zhou A, Hsi ED, Hussein M, Almasan A: Apo2L/ TRAIL and Bcl-2-related proteins regulate type I interferon-induced apoptosis in multiple myeloma. Blood 2001;98:2183-2192.

9 Kuenzli S, Bucher S, Saurat JH: Successful treatment of Schnitzler's syndrome with interferon alfa-2b. Dermatology 2002;205:74. 